\title{
Gender Bias in Living Donor Kidney Transplantation in Japan: a Questionnaire Survey in Spousal Renal Donors
}

\author{
Miyako Takagi
}

\begin{abstract}
Living donor nephrectomy for renal transplantation has become widespread as surgical techniques. A questionnaire survey of living transplantation donors who gave a kidney to their spouses was conducted to determine their perceptions of living donor kidney transplantation. In this survey, 2 of 3 kidneys were donated by wives. In general, men are breadwinners in the family and women are more often expected to act as donors. From the responses to the question "How much was your intention to become a donor?," it was clear that wife-donors had lesser intention to donate than husband-donors. In other words, the decision of wife-donors was more influenced by others. Donors were also asked their opinions regarding transplantation of surgically restored cancerous kidneys. This is currently not allowed in Japan. From the result, wife-donors were more tolerant of restored kidney transplantation than husband-donors. Transplantation using a previously cancerous donor kidney may offer some relief of pressure placed on family members, particularly wives, to donate.
\end{abstract}

Index Terms-Questionnaire survey, gender imbalance in living donor, donors' perceptions, restored kidney transplantation.

\section{INTRODUCTION}

At the end of March 2014, 12,875 patients were registered with the Japan Organ Transplant Network as seeking renal transplantations. These patients are waiting for transplantations from donors who are brain-dead or cardiac-arrested. It reportedly takes an average of approximately 14 years for patients to receive transplantation after registration. Some of the patients have removed their names from the waiting list and have given up because of their age and other reasons. As such, approximately 20,000 patients are thought to die every year while waiting for transplantation [1]. Because of the limited availability of cadaveric donor organs, kidneys must be procured from living donors. The Japan Society for Transplantation stipulates in its ethics guidelines that transplants with living donors are limited to patients' relatives. Approximately 1,300 renal transplantations are performed every year in Japan, and $85 \%$ of those are from living donors [2]. Consequently, the degree of dependence on transplantations from living donors is high compared with international norms.

Manuscript received June 9, 2014; revised August 8, 2014. This work was supported by a grant from Grants-in-Aid for Scientific Research (C) 23613009 of the Japanese Society for the Promotion of Science.

Miyako Takagi is with the University Research Center, Nihon University, 4-8-24, Kudan-minami, Chiyoda-ku, Tokyo 102-8275 Japan (e-mail: takagi.miyako@ nihon-u.ac.jp).
Spouses are an important source of living donor kidney grafts because despite poor human leukocyte antigen (HLA) matching, the graft survival rate is similar to that of parental donor kidneys [3]. The ethics of living donor transplantation have been frequently discussed, and live donor nephrectomy for renal transplantation has become widespread. Because surgical techniques and outcomes have improved, this practice has expanded. However, living donor transplantation presents an ethical dilemma, in which physicians must risk the life of a healthy person to save or improve the life of a patient.

While awaiting transplantation, all patients must receive dialysis treatment for survival. By the end of 2012, there were 309,946 individuals in Japan receiving dialysis for deteriorating kidney function [1]. In Japan, almost all dialysis treatment-related expenses are paid by the National Health Insurance. At present, the total sum of dialysis expenses in Japan amounts to 2 trillion yen (approximately 20 billion US dollars), and this greatly affects the country's remuneration of other important medical expenditures.

Many small renal tumors are nephrectomized in Japan, resulting in the disposal of an excessive number of discarded kidneys every year. It is thought that the use of discarded cancerous kidneys for transplantation may help to compensate for donor shortage. However, at present, this practice is disallowed in Japan because of a lack of evidence regarding outcomes, risks, and efficacy. Clinical research is ongoing to determine the feasibility of restored kidney transplantation as a method of alleviating the long waiting time and easing the suffering of patients who require transplantation.

\section{Methods}

Between January 2012 and March 2013, a questionnaire was sent to 3 hospitals: Tokyo Women's Medical University Hospital, Uwajima Tokushukai Hospital, and Kure Kyosai Hospital. In 2010, Tokyo Women's Medical University Hospital was at the top place in terms of the number renal transplantation surgeries performed in Japan (459 cases), Uwajima Tokushukai Hospital was at the third place (142 cases), and Kure Kyosai Hospital was at the $39^{\text {th }}$ place (18 cases) [4].

At 2 of these hospitals, a hospital worker sent the questionnaire to recipients who had undergone spousal renal donor transplantation, and respondents sent it back to the hospital. In another hospital, a hospital worker distributed the questionnaire to patients at a follow-up examination after transplantation, and respondents directly sent it back to our research center. In total, responses were obtained from 142 
donors. The questionnaire is provided in the Appendix. Only descriptive statistical analysis was performed. This study was approved by the ethical review committee in the Medical Department, Nihon University.

\section{RESULTS AND DISCUSSION}

\section{A. Gender Imbalance}

In total, 41 husbands and 99 wives were donors in this survey (there were 2 respondents who did not indicate their gender). Two of every 3 kidneys were donated by wives in this study, indicating a gender bias in living donors. As shown in Table I, for $67.7 \%$ of wife-donors, the majority of the family income $(70 \%-100 \%)$ was earned by husband-recipients. With the husband being the main or only breadwinner in the family, it is not difficult to imagine that women are more often expected to act as donors. In addition, in the United States, wife-donors were twice as common as husband-donors. A higher incidence of kidney disease in men, fear of losing the earning male member, and perception of renal donation as an extension of responsibility toward family have been suggested to be reasons for female domination among living donors [5].

TABLE I: WHAT IS THE PERCENTAGE OF RECIPIENT'S INCOME IN THE TOTAL FAMILY INCOME

\begin{tabular}{lrrrr}
\multicolumn{3}{c}{ FAMILY INCOME } \\
\hline \hline \multicolumn{1}{c}{ donor } & husband & \multicolumn{3}{c}{ wife } \\
\hline \hline $0 \%$ & $n$ & $\%$ & $n$ & $\%$ \\
$10-30 \%$ & 24 & 58.5 & 2 & 2.0 \\
$40-60 \%$ & 7 & 17.1 & 10 & 10.1 \\
$70-90 \%$ & 6 & 14.6 & 14 & 14.1 \\
$100 \%$ & 3 & 7.3 & 20 & 20.2 \\
no answer & 1 & 2.4 & 47 & 47.5 \\
\hline \hline
\end{tabular}

\section{B. How Much Was Your Intention to Become a Donor?}

In total, $85.4 \%$ of husband donors and $79.8 \%$ of wife donors responded that the offer to donate was completely voluntary $(100 \%)$. However, $7.3 \%$ of husband-donors and $14.1 \%$ of wife-donors answered that the decision to donate was partially influenced by someone $(90 \%-50 \%)$. Surprisingly, 1wife-donor answered her offer to donate was primarily based on the interference of others and her own intention was under $10 \%$ (Table II). These figures showed that some donors may not want to donate and may be pressured into donation by others.

TABLE II: HOW MUCH WAS YOUR INTENTION TO BECOME A DONOR?

\begin{tabular}{lcrrr}
\hline \multicolumn{1}{c}{ donor } & husband & \multicolumn{3}{c}{ wife } \\
\hline \hline $100 \%$ & $\mathrm{n}$ & $\%$ & $\mathrm{n}$ & $\%$ \\
$90-50 \%$ & 35 & 85.4 & 79 & 79.8 \\
$50-20 \%$ & 3 & 7.3 & 14 & 14.1 \\
$<10 \%$ & 1 & 2.4 & 3 & 3.0 \\
no answer & 0 & 0.0 & 1 & 1.0 \\
\hline \hline
\end{tabular}

As shown in Table III, living donors felt pressured by their husbands or wives, children, parents, parents-in-law, or close relatives (cases under $90 \%$ in Table II). The wife-donor who answered that her own intentions to donate were fewer than $10 \%$ felt pressured by her husband. We asked whether there was any domestic violence (including mental pressure by words) between couples. Two husband-donors and 2 wife-donors answered "yes." Nowadays, living renal transplantation is possible even between blood group-incompatible pairs. We asked whether this fact makes it difficult to refuse a request to become a donor. Two donors, who also reported domestic violence, answered "yes." Nephrologists need to take special care to rule out coercion whenever such situations arise.

TABLE III: WHOM Did You FEEL PRESSURE FROM, IN THE CASE UNDER $90 \%$ IN TABLE II

\begin{tabular}{llc}
\hline \hline & $n$ & $\%$ \\
\hline between husband and wife & 7 & 31.8 \\
offspring & 5 & 22.7 \\
parent-in-law & 2 & 9.1 \\
parent & 2 & 9.1 \\
close relatives & 1 & 4.5 \\
no answer & 5 & 22.7 \\
\hline \hline
\end{tabular}

\section{Anxiety for Having Only a Single Kidney}

In total, $26.8 \%$ of husband-donors and $36.4 \%$ of wife-donors were worried about having only a single kidney (Table IV). The wife-donors were more anxious about their health after kidney donation than husband-donors. One wife-donor wrote, as a free answer, that she wanted to withdraw as a donor before the surgery but was not able to disclose her concerns to the doctor. Data have shown that donors live as long as other healthy people [6]. However, data alone cannot relieve the uneasiness of the donor. After the removal of a kidney, a donor becomes chronic kidney disease (CKD) stage II; stage I is the normal condition and stage II is mildly reduced kidney function. People with CKD stage II typically require lifestyle modification and infrequently require treatment to halt the progression of CKD.

TABLE IV: WERE YOU WORRIED ABOUT HAVING ONLY A SINGLE KIDNEY

\begin{tabular}{lccrc}
\multicolumn{1}{c}{ donor } & husband & \multicolumn{3}{c}{ wife } \\
\hline \hline & $n$ & & \multicolumn{3}{c}{$n$} & $\%$ \\
\hline yes & 11 & 26.8 & 36 & 36.4 \\
no & 30 & 73.2 & 61 & 61.6 \\
no answer & 0 & 0.0 & 2 & 2.0 \\
\hline \multicolumn{1}{c}{ Two } & wife-donors & responded & that & physical and
\end{tabular}
psychological conditions were bad after transplantation and their relationship with their husbands were consequently strained. Health problems occurring after living renal transplantation have been correlated to increasingly negative interfamily relations [7].

\section{Experience with Living Donor Transplantation}

In total, $92.7 \%$ of husband-donors and $86.9 \%$ of wife-donors recognized living donor transplantation as ongoing medical care, while 2 wife-donors thought the medical care that they received was problematic (Table V). Fewer wife-donors than husband-donors regarded living 
donor renal transplantation as regular medical care. In this context, "medical care" is regular medical care used for a long term and "temporary medical care" is more likely to be changed to a different approach in the near future.

The function of a single kidney is approximately $70 \%-75 \%$ that of both kidneys. After transplantation, the living donor may suffer from high blood pressure or proteinuria, which may progress to heart disease and kidney disease. In addition, a person with a single kidney is more likely to be overweight, which can cause an additional decrease in renal function [8]. When we audited consent forms in Japan and the United States, there was no description about these long-term risks. If the true spirit of informed consent is to be met, potential living donors should be told all possible risks associated with becoming a donor.

TABLE V: WHAT DO YOU THINK ABOUT LIVING DONOR TRANSPLANTATION FROM YOUR EXPERIENCE

\begin{tabular}{lcccc}
\hline \multicolumn{1}{c}{ Tonor } & husband & \multicolumn{3}{c}{ wife } \\
\hline \hline & $n$ & $\%$ & $n$ & $\%$ \\
\hline recognized as medical care & 38 & 92.7 & 86 & 86.9 \\
recognized as temporary & 1 & 2.4 & 5 & 5.1 \\
medical care & 0 & 0.0 & 2 & 2.0 \\
had a problem as medical care & 1 & 2.4 & 1 & 1.0 \\
others & 1 & 2.4 & 5 & 5.1 \\
no answer &
\end{tabular}

The Swiss organ living donor health registry was initiated in 1993. A donor registry has existed in the Netherlands since 1998. In Australia and New Zealand, the Anzdata Living Donor Kidney Registry was established in 1997. A registry would provide a comprehensive and longitudinal database of living donors [9]. This data could be used to identify risk factors related to transplant outcome, donor psychosocial and physical complication rates, and long-term ramifications of living donation on the donor. Ultimately, this information can be used to more thoroughly support living donors and minimize risks. Because a living donor health registry does not exist in Japan, it may be necessary to summarize documents of other countries to show Japanese potential living donors.

\section{E. Opinion of Donors Regarding Restored Kidney Transplantation}

Total nephrectomy is often performed as a treatment for small renal tumors $(\leq 4 \mathrm{~cm})$. Many of these nephrectomized kidneys could be successfully transplanted after surgical restoration with satisfactory results [10]. However, the issue of cancer recurrence is a concern in surgically restored cancerous kidney transplantation. The 5-year recurrence rate of cancer after restored kidney transplantation remains undetermined. Nicol et al. supposed that it may be observed in less than 1 in 50 cases $(0.5 \%)$ [11]. However, the recurrence rate after radical or partial nephrectomy is reported to be $<6 \%$ [12]. In our survey, we asked recipients a question on the assumption that the 5-year recurrence rate after restored kidney transplantation was $6 \%$. This rate seems very high compared with the reality.

In response to the question "What do you think about restored kidney transplantation from your experience?," $78.0 \%$ of husband-donors and $82.8 \%$ of wife-donors recognized restored donor transplantation as medical care (Table VI). In response to the next question "If restored kidney transplantation had been possible when you underwent the procedure, would you have chosen living donor transplantation or restored kidney transplantation?," $61.0 \%$ of husband-donors and $52.5 \%$ of wife-donors wanted to choose living donor transplantation and $9.8 \%$ of husband-donors and $13.1 \%$ of wife-donors wanted to choose restored kidney transplantation (Table VII). From these results, wife-donors were more tolerant of restored kidney transplantation than husband-donors.

TABLE VI: WHAT DO YOU THINK ABOUT RESTORED KIDNEY TRANSPLANTATION FROM YOUR EXPERIENCE

\begin{tabular}{lcccc}
\hline \hline \multicolumn{1}{c}{ donor } & husband & \multicolumn{3}{c}{ wife } \\
\hline \hline & $n$ & $\%$ & $n$ & $\%$ \\
\hline recognized as medical care & 32 & 78.0 & 82 & 82.8 \\
recognized as temporary & 5 & 12.2 & 8 & 8.1 \\
medical care & 3 & 7.3 & 5 & 5.1 \\
had a problem as medical care & 0 & 0.0 & 1 & 1.0 \\
others & 1 & 2.4 & 3 & 3.0 \\
no answer &
\end{tabular}

As a free answer, a wife-donor expressed "I recognize the living donor transplantation; however, the feeling of loss in the donor is very strong. Restored kidney should be added to the donor pool." "My kidney was taken out of my healthy body, and it was a considerably hard experience. I hope restored kidney transplantation should be recognized as an alternative method."

TABLE VII: IF RESTORED KidNEY TRANSPLANTATION HAD BEEN POSSIBLE, WOULD YOU HAVE CHOSEN EITHER LIVING DONOR TRANSPLANTATION OR RESTORED KIDNEY TRANSPLANTATION

\begin{tabular}{lcccc}
\hline \hline \multicolumn{1}{c}{ donor } & husband & \multicolumn{3}{c}{ wife } \\
\hline \hline $\begin{array}{l}\text { I choose living donor } \\
\text { transplantation }\end{array}$ & $n$ & $\%$ & $n$ & $\%$ \\
$\begin{array}{l}\text { I choose restored kidney } \\
\text { transplantation }\end{array}$ & 4 & 61.0 & 52 & 52.5 \\
$\begin{array}{l}\text { I cannot decide which one } \\
\text { to choose }\end{array}$ & 10 & 24.4 & 13 & 13.1 \\
no answer & 2 & 4.9 & 9 & 9.1 \\
\hline \hline
\end{tabular}

Guidelines on Renal Transplantation (2009) published by the European Association of Urology [13] state the following: "Due to a low risk of recurrence, kidneys with small renal cell carcinoma (RCC) can be considered for local excision and transplantation after the recipient has given informed consent. The risk of RCC transmission to the contralateral kidney and/or to other organs is even lower." In the United States, the Middle East, and Asia, many living kidney transplants are performed. On the other hand, living donors are generally less used in Europe, where the option to use surgically restored cancerous kidneys may be preferred [7].

\section{CONCLUSIONS}

Nowadays, the traditional big family is being replaced by more nuclear families. Consequently, even if there are siblings and/or offspring, ties between relatives are getting weaker after marriage and only the spouse may be motivated 
to become a donor if the need arises. Many wife-donors in a previous study [14] reported that no other donor was available. A wife-donor experienced guilt about not wanting to be a donor. She thought that if transplantation was not performed and her husband died as a result, she would deeply regret her refusal to donate. Thus, she felt that she had no choice but to donate a kidney for saving her spouse's life. In our survey of dialysis patients [15], $28.0 \%$ of those who wanted living donor transplantation could not find a donor. In this context, living donor renal transplantation may be unfair.

In developing countries, women donate live-related and -unrelated kidneys more often, and they are less likely to receive a live kidney than men. They can be easily coerced to donate under social circumstances [16]. However, the gender bias in renal transplantation is not restricted to developing countries. It was reported that women were $28 \%$ more likely to donate a kidney than men even in advanced nations [17].

In this survey, $18.1 \%$ of wife-donors stated that their offer to donate was not partially based on their own intention $(<90 \%)$; this was twice as much as that of husband-donors $(9.7 \%)$. Surprisingly, 1wife-donor answered that her intentions to donate were under $10 \%$. These figures show that becoming a donor was partially influenced by husband, wife, children, parents, parents-in-law, or close relatives. This survey also showed that approximately $70 \%$ of wife-donors financially relied on husband-recipients. This is another major reason for kidneys being donated from the wife to the husband. Further investigation is required to understand the possible psychosocial or cultural reasons for this gender imbalance.

To overcome a universal shortage of organs, efforts have been made to explore new sources. One such area is the use of kidneys containing small tumors after resection of the neoplasm. A report supports the feasibility of utilizing surgically restored cancerous kidneys [18]. In that report, the patients who had lost their kidney because of tumors supported the use of the kidneys (93\%). The authors encouraged transplant surgeons to expand their comfort in using such organs. However, in such cases, recipients should be fully informed of the implications of the type of organ they are receiving. Because cancerous kidneys are being discarded anyway, fewer ethical issues may be associated with restored kidney transplantation compared with living donor transplantation. It is thought that using discarded cancerous kidneys for transplantation may help to compensate for donor shortage and to avoid unwilling living renal donors.

\section{APPENDIX}

Questionnaire:

1) The day when questionnaire was filled out.

2) Are you the wife-donor or husband-donor of the kidney?

3) How old was the recipient at the time of renal transplantation? (20-29, 30-39, 40-49, 50-59, 60-69, $\geqq 70$ years) / How old were you at the time of renal transplantation? $(20-29,30-39,40-49,50-59,60-69$, $\geqq 70$ years)

4) When was the transplant surgery performed?

5) How many years had you been married when the surgery was performed?
6) How long was the recipient on dialysis?

7) What is your religion?

8) What is the percentage of recipient's income in the total family income? $(0 \%, 10-30 \%, 40-60 \%, 70-90 \%$, $100 \%)$

9) How much was your intention to become a donor? $(100 \%, 90-50 \%, 50-20 \%,<10 \%)$

10) Whom did you feel pressure from in the case under $90 \%$ in the previous question? (between husband and wife, offspring, parent-in -law, parent, close relatives)

11) Was there any domestic violence (including mental pressure by words) between couples in a kidney offer?

12) Nowadays, living renal transplantation is possible even between blood group-incompatible pairs. Did this fact make it difficult to refuse a request to become a donor?

13) After kidney transplantation, what was your physical condition?

14) After kidney transplantation, what was your psychological condition?

15) Were you worried about having only a single kidney?

16) After kidney transplantation, did conjugal relations between you change?

17) What do you think about living donor transplantation from your experience?

18) Total nephrectomy is often performed as a treatment for small renal tumors $(\leqq 4 \mathrm{~cm})$. Many of these nephrectomized kidneys could be successfully transplanted after surgical restoration with satisfactory results. However this is currently not allowed in Japan because of the lack of necessary evidence. The issue of cancer recurrence is a concern in restored kidney transplantation. The 5-year recurrence rate of cancer after restored kidney transplantation remains undetermined and we estimated it to be $6 \%$. How do you think about restored kidney transplantations?

19) If those days when you underwent transplant, restored kidney transplantation was possible, what kind of choice did you do, living donor transplantation or restored kidney transplantation?

\section{ACKNOWLEDGMENT}

The author is deeply grateful to Dr. M. Mannami of the Department of Urology, Uwajima Tokushukai Hospital, Prof. K. Tanabe of the Department of Urology, Tokyo Women's Medical University, and Dr. N. Mitsuhata of the Department of Urology, Kure Kyosai Hospital for permitting distribution of the questionnaire.

\section{REFERENCES}

[1] S. Fujita, "Treatment for chronic renal failure; Japanese condition, world condition," Doctor's Network, Japan, no. 32, pp. 8-10, 2007.

[2] Japanese Transplant Association (NPO). [Online]. Available: http://www.jtr.ne.jp/isyokutoha/genjyo.html

[3] B. V. Shah, P. Rajput, V. Waghmare, and A. Aiyangar, "Spousal Kidney Transplant," Journal of Nephrology and Renal transplantation vol. 2, no. 1, pp. 16-22, 2009.

[4] On-Line Retrieval System for Japanese Hospital Information (Caloo). [Online]. Available: http://caloo.jp/rbhw/code/19

[5] G. T. Thiel, C. Nolte, and D. Tsinalis, "Gender Imbalance in living kidney donation in Switzerland," Transplantation Proceedings, vol. 37 , no. 2, pp. 592-594, 2005

[6] R. C. Rabin, "The reward for donating a kidney," The New York Times, June 11, 2013 
[7] G. Tellioglu, I. Berber, I. Yatkin et al., "Quality of life analysis of renal donors," Transplantation Proceedings, vol. 40, pp. 50-52, 2008

[8] Risk in the Kidney Donation. [Online]. Available: http://jin-ishoku.jp/donor/index.html

[9] The Need for a Living Donor Registry. [Online]. Available: http://www.livingdonor101.com/livingdonorregistry.shtml

[10] M. Mannami, R. Mannami, N. Mitsuhata, M. Nishi, Y. Tsutsumi, K. Nanba, and S. Fujita, 'Last resort for renal transplant recipients, 'restored kidneys' from living donors/patients," Am J Transplant, vol. 8, no. 4, pp. 811-8, 2008

[11] D. Nicol and S. Fujita, "Kidneys from patients with small renal tumors used for transplantation: outcomes and results," Curr Opin Urol. vol. 21, no. 5 , pp. $380-385,2011$

[12] H. V. Poppel, "Efficacy and safety of nephron-sparing surgery," International Journal of Urology, vol. 17, pp. 314-326, 2011

[13] Guidelines on Renal Transplantation, European Association of Urology, 2009

[14] M. Takagi, "Investigation on the perceptions of living donors regarding spousal renal donor transplantation," Journal of Life Sciences, vol. 7 , no. 11, pp. 1134-1142, 2013.

[15] M. Takagi, "Attitudes toward restored kidney transplantation among dialysis patients: responses to a questionnaire," American International Journal of Contemporary Research, vol. 3, no. 4, 2013.
[16] M. M. Bal and B. Saikia, "Gender bias in renal transplantation: are women alone donating kidneys in India?" Transplant Proc, vol. 39 , no.10, pp. 2961-3, 2007

[17] A. E. Luchtenburg, W. C. Zuidema et al., "Balanced gender distribution in living kidney donors," Organs and Tissues, no. 3, pp. 187-190, 2003

[18] M. A. Khurram, A. O. Sanni, D. Rix, and D. Talbot. Renal Transplantation with kidney Affected by Tumours. [Online]. Available: http://dx.doi.org/10.4061/2010/529080

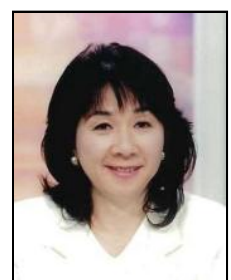

Miyako Takagi is a professor of University Research Center at Nihon University. Her research interests include ethical, legal and psychosocial aspect of organ transplantation, embryonic stem cell research and neuroethics. She is a member of Bioethics Committee in Japanese Cabinet Office, and also she is the vice president in Asian Bioethics Association. She received her Docteur d'Université ès Sciences, Université PARIS VII. 